\title{
Older people, mental health and learning
}

\section{Context: population and political}

The World Health Organization (2002) describes population aging as "one of humanity's greatest triumphs" as well as "one of our greatest challenges." Growth in the number of older people as a proportion of the total population (described as the graying of the world's population) is a global phenomenon. With increasing age the causes of death and disease change: in early life communicable diseases, nutritional deficiencies and maternal/ perinatal conditions are most important, but after midlife, chronic conditions assume increasing importance. Amongst the chronic conditions of later life, mental disorders feature prominently, the two most common being dementia and depression (Faculty of Old Age Psychiatry, 2006).

This demographic challenge, and the concerns about its political and economic implications (as well as social and health consequences), probably underlie increasing political interest in the U.K. in late life mental health, as illustrated by a series of high profile publications over recent years (Care Services Improvement Partnership, 2005; Office of the Deputy Prime Minister, 2006; Age Concern and The Mental Health Foundation, 2006; Age Concern, 2007; National Institute for Health and Clinical Excellence - Social Care Institute for Excellence (NICE-SCIE), 2007; National Audit Office, 2007; House of Commons Committee of Public Accounts, 2008). The report Dementia UK (Alzheimer's Society, 2007) attracted a lot of interest and concern with its projections of the anticipated growth in numbers of people with dementia in the U.K. and detailed examination of the financial costs of dementia. Lowin et al. (2001) estimated the direct costs of Alzheimer's disease in the U.K. to be greater than those of cancer, stroke and heart disease combined. The Department of Health has recently published a National Dementia Strategy for England (Department of Health, 2009).

\section{Context: mental health in later life}

Dementia becomes more prevalent with increasing age and, in broad figures, affects one person in 20 aged over 65 and one person in five aged over 80 (Hofman et al., 1991). The Alzheimer's Society

First published online 16 April 2009. (www.alzheimers.org.uk) estimates that there are currently 700,000 people with dementia in the U.K. and that this will increase to 1 million by 2025 . The most common forms of dementia are Alzheimer's disease $(62 \%)$ and vascular and mixed dementia (27\%) (Alzheimer's Society, 2007), but there are many other causes. Dementia can be viewed as a terminal illness and people will deteriorate until they need help with all the activities of daily living. There is no specific treatment for Alzheimer's disease or vascular dementia, although drug treatments are available which are of benefit to some people (NICE, 2007).

Depression is a common mental health challenge in older people: around $15 \%$ of people aged over 65 have a depressive syndrome (European Commission, 2004). However, a much smaller proportion, about $2 \%$, would meet criteria for a major depressive illness (European Commission, 2004). Depression is more common in care settings, including general hospitals (Wattis, 2008). Beeston (2006) points out that people over the age of 65 are more successful than any other age group in taking their own lives and about two-thirds of older people who kill themselves are depressed; despite this, the National Suicide Prevention Strategy for England (Department of Health, 2002) lacked a focus on older adults. In most Member States of the European Union suicide rates amongst older people are higher than in any other age group (Wahlbeck and Mäkinen, 2008).

Older people also present with a range of other disorders, including psychoses and substance misuse disorders (Hybels and Blazer, 2003).

\section{What is learning?}

Learning is the knowledge or skills acquired through study or by being taught. To learn is to be informed, to get to know, to gain knowledge, skill or ability. Learning can take many forms, including learning about health issues, such as the treatment and prevention of mental disorders. It is also the primary goal in an academic (i.e. formal or scholarly) sense, as in the case of the woman with recurrent depression following retirement who undertook a degree in Egyptology (personal communication), in the sense of developing new interests (for example, the man with recurrent depression in later life who enrolled on a computer course and the woman in 
her 80s who took up classes in life drawing (personal communications)), and in developing existing skills (for example, the man who had enjoyed attending a gym over many years who was supported to continue despite developing progressive dementia (personal communication)). We can understand learning as a process (McNamee, 2007) where knowledge is not a package transferred from one person to another but instead emerges from the interaction between the people involved. Teaching is also learning, as it is a process by which ideas evolve over time through the interactions between "teacher" and students. Taking a systems perspective this learning or teaching process will impact on other roles and relationships which the learner or teacher undertakes. Involvement in learning will alter how individuals see themselves and how others see them.

\section{The role of learning}

Age Concern (2008a) identifies six roles for learning:

- maintaining mental and physical health

- pursing interests and broadening horizons

- improving self-confidence

- gaining life skills

- reducing isolation, and

- contributing to the community.

These offer a useful framework. What evidence is there that engaging in learning activities enhances mental health in older adults? The World Health Organization (WHO) states that education in early life, combined with opportunities to engage in life-long learning can help people to develop the confidence and skills that will help them to adapt and remain independent as they grow older (WHO, 2002). Davey (2002) argues that lifelong learning assists the transition to retirement and later life. Glanz and Neikrug (1997) advocate that learning in later life should be regarded not as "leisure-time consumer activity" but as "social investment," since it encourages creativity, personal development and intellectual growth as well as combating ageism. Thus, older adults' learning can contribute to the life of the community as a whole: for example, a woman with recurrent anxiety and depression post-retirement undertook a course in food hygiene so that someone at her local community center was qualified and its work could continue (personal communication). Orte et al. (2007) maintain that education plays a fundamental role in quality of life and therefore fulfils a healthrelated function. Similarly, Schneider (2003) views learning as resulting in health-related behaviors: "learning can compensate for aging." Duay and Bryan (2006) state that learning is a coping strategy which helps people cope with stress and major events/transitions, and these may be related to physical and/or mental health. The National Service Framework Mental Health (Department of Health, 1999) stresses the role of education in mental health promotion and social inclusion, and the Social Exclusion Unit Report (Office of the Deputy Prime Minister, 2004) highlights the need for people with mental health problems to be able to access education.

One possible obstacle to engaging older adults with mental disorders in learning might be the prejudice amongst people of all ages that learning/curiosity/enquiry is for the young (or perhaps for those who will use their skills in paid employment). Attitudes to learning and involvement in learning are likely to differ between generations and the older people of today may have grown up at a time when there was an emphasis on earning ability and duty in a setting of more rigid gender roles and less career flexibility.

\section{Aspects of learning}

In relation to older people's mental health, the benefits of learning can be considered in three main areas:

1. Practical: developing life skills/adjusting to illness

2. Psychological: maintaining/developing self-confidence and setting personal goals

3. Social: social contact, avoiding isolation and engaging with the community.

\section{Practical aspects of learning}

Learning about an illness (physical or mental) or about how to maintain health and avoid illness is an important practical area, but practical aspects may involve learning new skills (including problem-solving skills), developing existing skills or acquiring knowledge not related to health/illness. One example is adjusting to or preparing for retirement. Retirement can be a loss event which may precipitate depressive illness (Pitt, 1998), so preparation/adjustment may prevent depression or, when an individual has already developed depression, addressing the transition to retirement might be part of treatment and relapse prevention. Practical skills learned may impact beneficially on other areas; for example, learning computer skills may impact socially by enabling elders whose mobility is limited to keep in contact with members of their families electronically or to make new social contacts. Learning has been regarded as a coping strategy (Duay and Bryan, 2006) in helping 
people deal with stress and helping them cope with major events and transitions (which would include retirement, major health challenges and bereavements). It can enable people to develop new skills which may compensate for some of the changes that come with aging; for example, learning electronic means of communication can enable people who are less mobile in later life to continue to keep in touch with existing family and friends, to make new friends, to access intellectual stimulation, and to contribute to the community; alternatively learning to drive may be another way to compensate for reduced mobility.

Case example (personal communication): a Gujerati-speaking woman with diabetes became unwell after failing to comply with her treatment. Despite mild memory problems related to cerebrovascular disease, she was helped to understand her treatment by repeatedly watching a video about diabetes with care staff in the home where she was in respite care.

\section{Psychological aspects of learning}

Learning can enhance self-esteem, self-efficacy and self-confidence (Mehrotra, 2003; Richeson et al., 2007). It may increase motivation - for example, if it is enjoyable it will reinforce a person's desire to engage in further learning - and it encourages personal and intellectual growth (Glanz and Neikrug, 1997). Davey (2002) studied older adults undertaking university courses and found that they were more likely to study interest-based subjects and to have personal development as a goal. Engagement in learning may well involve a person in examining and redefining their concept of self. Learning offers a means of helping individuals develop new goals for the future and may also involve them in developing new roles and adjusting existing roles: this links with social aspects as it will affect not only how they see themselves but also how other people see them.

Case example: a woman with Alzheimer's disease became involved in developing a university teaching program (Benbow et al., 2008) and delivered some teaching to the students, which was rated far more highly than the teaching of university staff. She later talked movingly about how this had brought some good out of her illness. She recognizes that her involvement impacted on a range of professional staff, but has also altered her family's view of her and her own view of herself.

\section{Social aspects of learning}

Involvement in learning activities may broaden an individual's social network and enrich existing social interactions, for example at a simple level by giving people more conversational topics which will itself be socially reinforcing. It may also allow people to contribute to their communities; this potentially reinforces the psychological benefits of learning by impacting on an individual's self-esteem.

Case example (personal communication): the daughter of a depressed and socially isolated elderly woman said that she dreaded visiting her mum as she never had anything to talk about. After her mum started to go to a day center, where she developed an interest in artwork, her daughter reported that she found their time together more enjoyable as her mum talked about her new interest.

An example of all three aspects of learning is Peter aka geriatric1927 who is a serial YouTube blogger and has his own website (http://www. askgeriatric.com). $\mathrm{He}$ is a member of the internationally known band and social experiment The Zimmers, and is involved in silversurferadvocates. co.uk. He writes on the web that this is

\begin{abstract}
"what this project is all about... to get the message out there of the joys of computing and pointing out all of the benefits. And let's not forget, apart from the pleasures, there are health benefits that accrue when the mind as well as the body is used and stretched."
\end{abstract}

He notes the practical difficulties of learning how to use a computer and learning what you can do with a computer. In an interview on YouTube he talks about the social benefits, about the community he has discovered through YouTube, "individual friends ... people you become attached to ... people come to visit." His ability to use his computer has given him a new sense of purpose and a desire to communicate with the online community. His $48,000+$ subscribers and 2.2 million hits (as of 5 September 2008) testify to the fact that the community is listening, and, in the exchange, both parties are learning.

\section{Application of learning to older adults' mental health}

These three aspects of learning can be related to:

- the prevention of illness (health promotion),

- the treatment of illness,

- the prevention of relapse/promotion of mental health amongst people with ongoing mental health problems.

\section{Prevention of illness (health promotion)}

Learning about illness and the effect of a healthy lifestyle should have a beneficial impact on future health. With regard to depressive illness in later life, Age Concern (2008b) has recently published 
a report which argues that education programs are needed that are aimed at older people and their families so that they know how to recognize and treat depression.

Involvement in other learning opportunities may involve people in being more active physically which will impact on their physical and mental health. If they make more social contacts it might reduce social isolation and loneliness: this may increase the likelihood of having close confiding relationships and a supportive social network with resulting benefits to mental health (Emmerson et al., 1989: Turvey et al., 2002). Alongside these benefits, a re-evaluation of the individual's role in late life may increase their psychological resilience. These impacts acting together may be able to protect against depressive disorders.

The European Commission Consensus paper on Mental Health in Older People (Jané-Llopis and Gabilondo, 2008) notes that there is evidence that involvement in meaningful activities (of various sorts) has been shown to improve the mental health of older people and contributes to wellbeing in later life, as do exercise and measures which maintain older adults' engagement with the community.

There is increasing evidence that the risk of dementia in later life may be minimized by maintaining physical and social activity and intervening earlier in life to modify major risk factors including hypertension, smoking, high blood cholesterol levels, and diabetes mellitus. Fratiglioni et al. (2007) note that people with less education are at higher risk of developing dementia and argue that intellectual stimulation protects against dementia. They regard an active life for older people (including mentally, socially and physically stimulating activities) as an important strategy in dementia prevention.

Learning could therefore play a potential role in prevention of both dementia and depressive disorder in later life and the promotion of mental (and physical) well-being.

\section{Treatment of mental disorder}

Moniz-Cook (2006) wrote about mental activity (or "mental exercise") as a psychological therapy for dementia but notes that there is confusion about what this might mean. She describes a broad range of activities that might come under this heading. The National Service Framework for Older People (Department of Health, 2001) recommends that the treatment of dementia "always involves" non-drug treatments such as mental exercise. Engagement in learning opportunities could constitute "mental exercise."
Richeson et al. (2007) reported an interesting study of a small group of people with early dementia who were offered a 13-week adult education class on health promotion. They found that it influenced measures of self-efficacy, mood and mental status and that the people concerned were interested in learning, growing and making connections despite their illness.

Dijkstra et al. (2006) demonstrated that people with dementia (with Mini-mental State Examination scores of 11-23, mean 17.8) could successfully teach students how to prepare recipes. They suggest that such success may impact on quality of life and feelings of self-worth as well as contributing to more rewarding social interactions. This is an illustration of older people (with dementia) as an untapped source of knowledge: tapping into that knowledge benefits both the older adults (who discover that they have unsuspected talents and wisdom) and the people who learn from them. Similarly Phinney et al. (2007) found that meaningful activities contribute to maintaining autonomy and personal identity amongst people with mild to moderate dementia.

These findings raise the question of whether engagement in learning/teaching could form part of dementia treatment in the future.

Simone and Haas (2007) investigated the influence of learning on mood amongst a group of older students attending classes at a university lifelong learning institute and found an improvement in mood at the end of the class. Although this study was open and uncontrolled it raises another interesting issue relevant to depressive illness: if mood improves following a learning experience in non-depressed older adults, might the same benefit occur in older adults with depression?

\section{Prevention of relapse}

Depressive illness in late life tends to be a relapsing disorder and the arguments regarding the role of learning in health promotion are equally applicable to the prevention of future episodes in someone with a history of depressive illness in late life. Similarly health promotion in someone with a diagnosis of dementia could involve a role for learning. Extending social networks and social support, improving self-esteem and developing skills are likely to decrease vulnerability to future relapses.

\section{Conclusions}

Learning may benefit older people regardless of whether they have a mental health problem, and there is no reason to think that people with mental 
health problems in later life will benefit less than those without. It would seem more likely that they might gain more benefit, and there are some interesting studies which support this hypothesis. Therefore, opportunities for learning should be considered as part of mental health promotion in later life, and in connection with the management of people with existing mental health problems. These areas are assuming increasing importance as the world population grays and mental health disorders of later life become an increasing public health challenge. A recent paper in the $B M \mathcal{F}$ (Butler et al., 2008) argued for a concerted effort to slow down aging - learning might have a role here too.

There has been surprisingly little research focused on the role of learning in relation to older people's mental health and a number of interesting questions await answers:

- How is the process of learning beneficial?

- What is different about people who engage in learning in later life?

- Who will benefit from engagement in learning?

- How can clinicians use learning to promote and maintain mental health in older adults?

\section{Conflict of interest}

None.

\section{Acknowledgments}

This paper was produced for, and presented at, the third seminar in an ESRC seminar series entitled Older People, learning and Society based at Leicester University, Leicester, U.K. My thanks go to those people who have discussed these ideas with me at the seminar and beforehand; to Kath, who has been an inspiration, and to Aled, who has contributed ideas and introduced me to geriatric 1927 .

\section{SUSAN MARY BENBOW}

Centre for Ageing \& Mental Health, Staffordshire

University, Stafford, U.K.

Email:drsmbenbow@aol.com

\section{References}

Age Concern and the Mental Health Foundation (2006). Promoting Mental Health and Well-being in Later Life. A First Report from the UK Inquiry into Mental Health and Well-being in Later Life. Available at: http://www.ageconcern.org.uk/ AgeConcern/report_mentalhealthandwellbeing.asp (last accessed 22 February 2009).
Age Concern (2007). Improving Services and Support for Older People with Mental Health Problems. The Second Report from the UK Inquiry into Mental Health and Well-being in Later Life. Available at: http://www.ageconcern.org.uk/ AgeConcern/Documents/full_report.pdf (last accessed 22 February 2009).

Age Concern (2008a). "Keeping the Grey Matter Ticking Over”. Learning after the Age of 50. Available at: http:// www. ageconcern.org.uk/AgeConcern/BAF033B378C3478AA006D78F47282865.asp (last accessed 22 February 2009).

Age Concern (2008b). Undiagnosed, Untreated, At Risk. The Experiences of Older People with Depression. Available at: http://www.ageconcern.org.uk/AgeConcern/Documents/ PA0130708_depression_campaign_report.pdf (last accessed 22 February 2009).

Alzheimer's Society (2007). Dementia UK. Available at: http://www.alzheimers.org.uk/site/scripts/download_info. php?fileID=2 (last accessed 22 February 2009).

Beeston, D. (2006). Older People and Suicide. Available at: http://www.westmidlands.csip.org.uk/silo/files/suicidein-elders-report.doc (last accessed 22 February 2009).

Benbow, S. M., Taylor, L. and Morgan, K. (2008). Multiple perspectives: involving users and carers in educating health and social care professionals. Quality in Ageing, 9 (2), 12-17.

Butler, R. N. et al. (2008). New model of health promotion and disease prevention for the 21 st century. BMF, 337, 149-150.

Care Services Improvement Partnership (2005). Everybody's Business. Integrated Mental Health Services for Older Adults: A Service Development Guide. Available at: http://kc.csip.org.uk/upload/everybodysbusiness.pdf (last accessed 22 February 2009).

Davey, J. A. (2002). Active ageing and education in mid and later life. Ageing and Society, 22, 95-113.

Department of Health (1999). National Service Framework for Mental Health: Modern Standards and Service Models. Available at: http://www.dh.gov.uk/en/ Publicationsandstatistics/Publications/ PublicationsPolicyAndGuidance/DH_4009598 (last accessed 22 February 2009).

Department of Health (2001). National Service Framework for Older People. Available at: http://www.dh.gov.uk/en/ Publicationsandstatistics/Publications/ PublicationsPolicyAndGuidance/DH_4003066 (last accessed 22 February 2009).

Department of Health (2002). National Suicide Prevention Strategy for England. Available at: http://www.dh.gov.uk/en/ Publicationsandstatistics/Publications/ PublicationsPolicyAndGuidance/DH_4009474 (last accessed 22 February 2009).

Department of Health (2009). Living Well with Dementia: A National Dementia Strategy. Available at: http://www.dh. gov.uk/en/socialcare/deliveringadultsocialcare/olderpeople/ nationaldementiastrategy/index.htm (last accessed 22 February 2009).

Dijkstra, K., Bourgeois, M., Youmans, G. and Hancock, A. (2006). Implications of an advice-giving and teacher role on language production in adults with dementia. Gerontologist, 46, 357-366. 
Duay, D. L. and Bryan, V. C. (2006). Senior adults' perceptions of successful aging. Educational Gerontology, 32, 423-445.

Emmerson, J. P., Burvill, P. W., Finlay-Jones, R. and Hall, W. (1989). Life events, life difficulties and confiding relationships in the depressed elderly. British fournal of Psychiatry, 155, 787-792.

European Commission (2004). The State of Mental Health in the European Union. Available at: http://www.msc.es/ organizacion/sns/planCalidadSNS/pdf/excelencia/salud mental/opsc_est18.pdf.pdf (last accessed 22 February 2009).

Faculty of Old Age Psychiatry (2006). Raising the Standard. Available at: http://www.rcpsych.ac.uk/PDF/ RaisingtheStandardOAPwebsite.pdf (last accessed 22 February 2009).

Fratiglioni, L., Winblad, B. and von Strauss, E. (2007). Prevention of Alzheimer's disease and dementia: major findings from the Kungsholmen Project. Physiology and Behavior, 92, 98-104.

Glanz, D. and Neikrug, S. (1997). Seniors as researchers in the study of aging: learning and doing. Gerontologist, 37, 823-826.

Hofman, A. et al. (1991). The prevalence of dementia in Europe: a collaborative study of 1980-1990 findings, Eurodem Prevalence Research Group. International fournal of Epidemiology, 20, 736-748.

House of Commons Committee of Public Accounts (2008). Improving Services and Support for People with Dementia Sixth Report of Session 2007-08. London: The Stationery Office.

Hybels, C. F. and Blazer, D. G. (2003). Epidemiology of late-life mental disorders. Clinics in Geriatric Medicine, 19, 663-696.

Jané-Llopis, E. and Gabilondo, A. (eds). (2008). Mental Health in Older People. Consensus Paper. Luxembourg: European Communities. Available at: http://www. ec-mental-health process.net/pdf/mental_health_in_ older_people_consensus_paper.pdf (last accessed 22 February 2009).

Lowin, A., Knapp, M. and McCrone, P. (2001). Alzheimer's disease in the UK: comparative evidence on cost of illness and volume of health services research funding. International Fournal of Geriatric Psychiatry, 16, 1143-1148.

McNamee, S. (2007). Relational practices in education: teaching as conversation. In H. Anderson and D. Gehart (eds.), Collaborative Therapy: Relationships and Conversations that Make a Difference (pp. 313-335). London: Routledge.

Mehrotra, C. M. (2003). In defense of offering educational programs for older adults. Educational Gerontology, 29, 645-655.

Moniz-Cook, E. (2006). Cognitive stimulation and dementia. Ageing and Mental Health, 10, 207-210.

National Audit Office (2007). Improving Services and Support for People with Dementia. Available at: http://www.official- documents.gov.uk/document/hc0607/hc06/0604/0604.asp (last accessed 22 February 2009).

NICE (2007). Donepezil, Galantamine, Rivastigmine (Review) and Memantine for the Treatment of Alzheimer's Disease (Amended). Available at: http://www.nice.org.uk/ guidance/TA111 (last accessed 22 February 2009).

NICE-SCIE (2007). Dementia: The NICE-SCIE Guideline on Supporting People with Dementia and their Carers in Health and Social Care. National Clinical Practice Guideline Number 42. Available at: http://www.nice.org.uk/cg42 (last accessed 22 February 2009).

Office of the Deputy Prime Minister (2004). Mental Health and Social Exclusion. Social Exclusion Unit Report. Available at: http://www.socialinclusion.org.uk/publications/ SEU.pdf (last accessed 22 February 2009).

Office of the Deputy Prime Minister (2006). A Sure Start to Later Life Ending Inequalities for Older People. Social Exclusion Unit Final Report. Available at: http://www. communities.gov.uk/publications/corporate/surestart (last accessed 22 February 2009).

Orte, C., March, M. X. and Vives, M. (2007). Social support, quality of life, and university programs for seniors. Educational Gerontology, 33, 995-1013.

Phinney, A., Chaudhury, H. and O'Connor, D. L. (2007). Doing as much as I can do: the meaning of activity for people with dementia. Aging and Mental Health, 11, 384-393.

Pitt, B. (1998). Coping with loss: loss in late life. BMF, 316, $1452-1454$

Richeson, N. E., Boyne, S. and Brady, E. M. (2007) Education for older adults with early-stage dementia: health promotion for the mind, body, and spirit. Educational Gerontology, 33, 723-736.

Schneider, K. (2003). The significance of learning for aging. Educational Gerontology, 29, 908-923.

Simone, P. M. and Haas, A. (2007). The influence of lifelong learning on mood. LLI Review, 2, 36-42. Available at: http://usm.maine.edu/olli/national/pdf/LLI-Review2007.pdf (last accessed 22 February 2009).

Turvey, C. L. et al. (2002). Risk factors for late-life suicide: a prospective, community-based study. American fournal of Geriatric Psychiatry, 10, 398-406.

Wahlbeck, K. and Mäkinen, M. (eds). (2008). Prevention of Depression and Suicide. Consensus Paper. Luxembourg: European Communities. Available at: http://ec.europa.eu/ health/ph_determinants/life_style/mental/docs/consensus_ depression_en.pdf (last accessed 22 February 2009).

Wattis, J. P. (2008). Affective disorders in the new millennium. In S. Curran and J. P. Wattis (eds.), Practical Management of Affective Disorders in Older People: A Multi-professional Approach (pp. 1-16). Oxford: Radcliffe Publishing.

World Health Organization (2002). Active Ageing: A Policy Framework. Available at: http://whqlibdoc.who.int/hq/2002/ WHO_NMH_NPH_02.8.pdf (last accessed 22 February 2009) 